\title{
Incisional Hernia of Elective Midline Caesarean Section: Incidence and Risk Factors
}

\author{
HASAN AL- DAHAMSHEH MD*
}

\begin{abstract}
Objective: To analyze the incidence and risk factors for development hernia after elective lower midline caesarean section(EIMCS).

Method: A prospective cohort study of 284 women for development of incisional hernia after repeated elective midline CS. Patients enrollment done from April $13^{\text {th }} 2001$ and December $12^{\text {th }}$ 2002. follow up to two years for hernia development. Hernias were identified radiographically or during physical exam. 2-year hernia rates were calculated. Patients were distributed in two groups, study group consisted of women who had incisional hernia and control group consisted from women who had not within 2-years postoperatively. Within the two groups potential risk factors (age, body mass index (BMI), parity, number of previous cesareans, chronic cough, diabetes mellitus(DM), heart disease, low serum albumin, type of previous incision, anesthesia type, presence of postoperative fever and wound complications) were collected and statistically analyzed with the development of incisional hernia $(I H)$.

Setting: Prince Hashem Ben Al-Hussein Hospital, Jordanian Royal Medical Services of Jordan /Zarqa.

Results: The 2-year hernia was $5.6 \%$. Independent risk factors of IH development include: increase in number of previous CSs, wound complications and obesity.

Conclusion: An incisional hernia is higher than previously estimated in women undergoing EIMCS. Counseling on the family size will reduce the chance for further CS with its associated risk. Also measures to reduce wound infection after surgery may reduce the incidence of incisional hernia following EIMCS.
\end{abstract}

Keywords : Elective lower midline cesarean section(ELMCS), Incisional hernia, wound complication

\section{Introduction}

The accurate incidence of incisional hernia after midline cesarean section is unknown. Incidence of $1,3 \%$ to $5.4 \%$ had been reported $1,2,3,4$. Greater than $50 \%$ of recognized incisional hernias are diagnosed within the first year after surgery, and approximately $80 \%$ are diagnosed within the first 3 years ${ }^{5}$. The rate of repeated cesarean section has increased gradually in all parts of the world ${ }^{6,7}$ as it became more acceptable and safe. In the United States, more than one-fifth of all births are by caesarean section and about one-third of all caesareans are an elective repeat operation ${ }^{8,9}$.
A variety of factors have been implicated in wound failure, including obesity and wound infection, early wound dehiscence, surgical technique, immunosuppressant therapy, aneamia, diabetes mellitus, malnutrition, jaundice, and azotaemia $10,11,12,13,14$. The most common mechanism of hernia formation in the abdominal midline is in the postoperative setting. The simplest theoretical scenario of hernia development is that a traumatized tissue lose a portion of its structural integrity, allowing protrusion of an organ or viscera into a region that is not its normal location ${ }^{15}$. Recurrent trauma of tissues as it happened with repeated cesarean sections would cause further weakness of abdominal wall, consecutively prone to hernia formation .

* From the departments of obstetric \& Gynecology/ Royal Medical Services. Correspondence should be addressed to Dr. Hasan Al- Dahamsheh, 11733, Prince Hashem Hospital, P.O box (134), Email: <dhamshdr66@yahoo.com>, Mobile: +962777343456 
After a review of publications on caesarean section in Jordan it is obvious how little importance is given to this late consequence despite the increasing rate of caesarean section ${ }^{16}$. Therefore, we decided to evaluate the incidence and the risk factors of $\mathrm{IH}$ in patients undergoing EIMCS .

\section{Methods}

\section{Clinical trial design}

A prospective cohort study conducted at Prince Hashem Ben Al-Hussein hospital (Zarqa, Jordan). Between April 13 ${ }^{\text {th }} 2001$ and December $12^{\text {th }} 2008$ and after obtaining written informed consent from all participants. Study participants were recruited from pregnant women admitted and required an elective midline CS( ELMC) duo to previous two or more CSs.

\section{Eligibility criteria}

All procedures performed by seniors in our unit with fascia closure with \#1 Loop PDS in a mass closure fashion with the goal of a 4:1 suture length to wound length ratio. Reasons for exclusion from the study include the following: use of subcutaneous drains, incomplete data, difficult to contact(phone or appointment to the clinic, those with immune deficiency and connective tissue disorders or any medical illness requiring immunosuppressive therapy and those with previous anterior abdominal wall incisional hernia. those who withdrew from the study for any reason before the end of the required 2-years follow-up or get pregnant during the follow up period. All subjects enrolled into the study freely decided to participate and gave written, signed informed consent.

\section{Study interventions}

Study participants were scheduled for ELMCS before study enrollment. Demographic, medical history, laboratory, perioperative, operative, and surgical outcomes data were collected prospectively over a minimum follow up period of 2 years postoperative. Demographic variables included age, body mass index (BMI) and parity. Medical history data included number of previous CS and type of this scar (pfennensteil or midline), diabetes mellitus, gestational diabetes, heart disease, history of chronic cough, history of smoking. Laboratory data recorded at time of study entry included preoperative albumin level. Perioperative data collected included type of anesthesia(general or spinal), operative time (minutes from time of laparotomy incision to closure) and intraoperative or postoperative blood transfusion, fever and local wound complications(cellulitis, seroma, infection, hematoma and dehiscence). The primary outcomes variable was the presence of incisional hernia (palpable incisional fascial defect e" $2 \mathrm{~cm}$ in diameter, or visible bulge in the laparotomy incision) within 2years of operation. .

\section{Follow-up}

Study subjects were admitted, consented to operation, and underwent ELMCS. All study subjects were followed for a minimum of 2 years for development of incisional hernia. Patients asked to attend our clinic every six moths or at any time if she notes a problem from the scar. The primary end points of this study were development and time to development of incisional hernia. Incisional hernias were diagnosed either by imaging or by physical exam. Medical records, including operative reports, , radiologic images and reports, and laboratory results, were reviewed and data were distracted. We calculated the rate of hernia within 2 years of the procedure.

\section{Statistical methods}

Differences in baseline characteristics were evaluated using Fisher's exact test (2-tailed) for categorical variables and the Wilcoxon rank sum test for continuous or ordinal data. Continuous data were presented as means with standard deviations (Mean \pm SD). Significance was determined at the $p<0.05$ level (2-tailed). Using a set of preoperative and operative risk factors as independent variables and development of incisional hernia as a dependent variable and the primary outcomes defined as presence of incisional hernia at the midline laparotomy site within 2 years of operation. The variables documented for each case include: age, body mass index(BMI), parity, number of previous cesareans, smoking, history of chronic cough, diabetes mellitus(DM),gestational diabetes (GD), heart disease, albumin level, type of anesthesia(general or spinal), previous CS incision, (pfennensteil vs. midline) perioperative blood transfusion and local wound complications(cellulitis, seroma, infection, hematoma and dehiscence).

Each factor found to be significant on univariate analysis were included in the multivariate model. Multivariate analysis was performed with binary logistic regression. Statistical analysis was performed using the Statistical Package for the Social Sciences (SPSS) for Windows version 17.0 (SPSS Inc, Chicago, Illinois). 


\section{Results}

The study was initiated in October 2004. Enrollment ended in April 2006 on three hundred and nineteen patients. We excluded $13(4 \%)$ because of incomplete follow up within 2 years postoperative, 8 (2.5\%)because of incomplete data, and 14 (4.3\%) because they get pregnant within 2 years of operation.

Table 1 show the parameters of our group study. With a mean follow-up time for the study population 20.6 \pm 3.3 months, a total of 16 (5.6\%) women developed incisional hernia and 268 (94.4\%) did not develop incisional hernia, three cases $(12.5 \%)$ of $\mathrm{IH}$ were asymptomatic.
All means of under study factors were compared between the two groups (women who developed versus women who did not develop IH ) table 2. Six factors found to be of significant importance within the group who developed $\mathrm{IH}$ by univariate analysis : number of previous CSs $(p<.0001)$, BMI $(p<.0001)$, parity $(p=.05)$, DM $(p=.05)$, chronic cough $(p=.04)$ and wound infection $(p=.003)$. But on multivariate analysis three factors of six factors mention above remain significant : CSs $(p<.001)$, BMI $(p<.001)$, and wound infection $(p=.002)$ table 2.

The other factors (age, previous incisional scar, gestational diabetes, preoperative low albumin level, type of anesthesia, duration of operation, perioperative blood transfusion and postoperative fever) were not significant table 2 .

Table-I

Demographic data

\begin{tabular}{ll}
\hline Total number of patients & 284 \\
\hline Age(year) (mean \pm SD)(range) & $33.3 \pm 6.5(23-28)$ \\
Body mass index( kg/m2) (mean \pm SD)(range) & $26.4 \pm 3.3(18-33)$ \\
Parity (mean \pm SD)(range) & $3.6 \pm 1.5(2-11)$ \\
Number of Previous CSs (mean \pm SD)(range) & $3.2 \pm 1.2(2-6)$ \\
Type of previous scar & \\
Pfannenstiel & $110(38.7 \%)$ \\
Midline & $174(61.3 \%)$ \\
Non smoker & $196(69 \%)$ \\
Light smoker & $53(18.7 \%)$ \\
Smoker & $35(12.3 \%)$ \\
Asthma & $39(13.7 \%)$ \\
Diabetes Mellitus & $19(6.7 \%)$ \\
Gestational Diabetes & $36(12.7 \%)$ \\
Heart disease & $23(8.1 \%)$ \\
Preoperative Albumin level (mg/dl) (mean \pm SD) & $2.6 \pm 0.5$ \\
Type of_Anesthesia & \\
General & $212(74.6 \%)$ \\
Spinal & $72(25.4 \%)$ \\
Operative Time (Minute) (mean \pm SD)(range) & $55.2 \pm 16.5(35-120)$ \\
Blood transfusion & $19(6.7 \%)$ \\
Postoperative fever & $29(10.2 \%)$ \\
Wound_complication & $14(4.9 \%)$ \\
Superficial infection & $12(4.2 \%)$ \\
Hematoma & $7(2.5 \%)$ \\
Seroma & $2(0.7 \%)$ \\
Wound dehiscence & \\
\hline
\end{tabular}


Table-II

Hernia versus no hernia group: patient demographics and characteristics

\begin{tabular}{|c|c|c|c|c|}
\hline riables & $\begin{array}{c}\text { Incisional } \\
\text { hernia } \\
\text { group }(n=16)\end{array}$ & $\begin{array}{c}\text { No incisional } \\
\text { hernia } \\
\text { group }(n=268)\end{array}$ & $\begin{array}{c}\text { Univariate } \\
\text { analyses) } \\
\text { P value }\end{array}$ & $\begin{array}{c}\text { Multivariate } \\
\text { analyses } \\
\text { P value }\end{array}$ \\
\hline Age (mean \pm SD) (year) & $32 \pm 4.9$ & $33.3 \pm 6.6$ & .43 & .08 \\
\hline BMI (mean \pm SD) $(\mathrm{kg} / \mathrm{m} 2)$ & $29.6 \pm 2.7$ & $26.2 \pm 3.2$ & $<.0001$ & $<.0001$ \\
\hline Parity(mean $\pm S D)$ & $4.6 \pm 1.4$ & $3.6 \pm 1.8$ & .049 & .18 \\
\hline $\begin{array}{l}\text { Number of previous cesareans } \\
(\text { mean } \pm \mathrm{SD})\end{array}$ & $4.2 \pm 1.3$ & $3.1 \pm 1.2$ & .006 & $<.0001$ \\
\hline \multicolumn{5}{|l|}{ Type of previous } \\
\hline scar Pfannenstiel & $4(25 \%)$ & 106(39.7\%) & .24 & .31 \\
\hline Midline & $12(75 \%)$ & $161(60.3 \%)$ & & \\
\hline Non smoker & $10(62.5 \%)$ & 193(72\%) & .65 & .49 \\
\hline Infrequent smoker & $4(25 \%)$ & $43(16 \%)$ & .06 & \\
\hline Regular smoker & $2(12.5 \%)$ & $32(12 \%)$ & .07 & \\
\hline Chronic cough & $5(31.3 \%)$ & $34(12.7 \%)$ & .04 & .58 \\
\hline Gestational & $3(18.8 \%)$ & $16(6 \%)$ & .13 & .71 \\
\hline Diabetes & $5(12.5 \%)$ & $8(3.2 \%)$ & .048 & .82 \\
\hline \multicolumn{5}{|l|}{ Diabetes Mellitus } \\
\hline Heart disease & $2(12.5 \%)$ & $21(7.8 \%)$ & .51 & .93 \\
\hline Anesthesia type & $11(68.7 \%)$ & $201(75 \%)$ & .58 & .69 \\
\hline General & $5(31.3 \%)$ & $67(25 \%)$ & & \\
\hline \multicolumn{5}{|l|}{ Spinal } \\
\hline Operative time (mean $\pm S D$ ) (minute & $64.2 \pm 20.8$ & $63.7 \pm 21.6$ & .89 & .47 \\
\hline Blood transfusion N(\%) & $2(12.5 \%)$ & $17(6.3 \%)$ & .39 & .17 \\
\hline Level of albumin (mean \pm SD) $(\mathrm{mg} / \mathrm{dl})$ & $2.5 \pm 0.36$ & $2.6 \pm 0.46$ & .12 & .35 \\
\hline Presence of fever & $3(18.8 \%)$ & $26(9.7 \%)$ & .25 & .49 \\
\hline \multicolumn{5}{|l|}{ Wound infection } \\
\hline Cellulitis & $3(18.8 \%)$ & $11(13.5 \%)$ & .21 & \\
\hline Hematoma & $2(12.5 \%)$ & 10(11.3\%) & .89 & .002 \\
\hline Seroma & $3(18.8 \%)$ & $6(8.5 \%)$ & $<.0001$ & \\
\hline Wound dehiscence & & $2(0.7 \%)$ & & \\
\hline
\end{tabular}

\section{Discussion}

Ventral hernia, a well established complication of midline laparotomy, is defined as an acquired protrusion through the anterior abdominal wall fascia ${ }^{16}$ .There is insufficient and conflicting reports on the frequency of incisional hernias in CS and, indeed, in ELMCS. Earlier studies showed rates of incisional hernia of $3.2 \%{ }^{1}, 5.4 \%{ }^{2}$ and $5.2 \%{ }^{4}$ for midline CS.
However the incidence was slightly higher on our cohort study and it was $5.6 \%$, a possible explanation for this discrepancy is, that all women in our cohort study group were with previous two or more CSs .

In this study several factors were evaluated to determine which one independently increase the likelihood of an incisional hernia post midline $C S$ table1. In agreement with previous studies in this area ${ }^{1,4}$, our 
data revealed that the most important constant and independent factor is the repetition frequency of caesarean section table 2 . With the increasing in number of this operation, it is expected to increase the likelihood of hernia formation.

Obesity and wound infection are apparently associated factors in surgery, and its generally accepted that morbidly obese patients have a higher risk of wound infection, which, in turn, leads to an increased incidence of incisional hernias. However there were conflicting reports about the role of wound infection as causative for $\mathrm{IH}$, in particular long term hernia formation. While studies ${ }^{18,19,20}$ confirm that and others does not 21,22 . In this present study we found that increased BMI and wound complication were independent risk factor for $\mathrm{IH}$ within the 2-years cohort study table 2 . This may be the result of impaired collagen synthesis at infected wound sites.

Previous studies recognized that the presence of diabetes mellitus is a risk factor of incisional hernia occurrence ${ }^{21}$. Studies of such comorbidity are inundated by bias, lack of statistical power, and reporting issues. The best current evidence, however, does not suggest diabetes mellitus dramatically affect incisional hernia rate ${ }^{18}$. In our study nearly half of diabetic patients(13) developed hernia later, which is significant in comparison with non diabetic. Although the sample size of this subgroup is too small to make reliable estimate.

There is disagreement about whether smoking influence the rate of incisional hernia. Some studies found that smoking influence the rate of $\mathrm{IH}^{23,24}$, while other researchers did not confirm this conclusion ${ }^{18}$. Our study could not ensure that smoking alters considerably the rate of incisional hernia postcaesarean section.

While the remaining factors in our study (age, parity, previous incisional scar, gestational diabetes, preoperative low albumin level, type of anesthesia, duration of operation, perioperative blood transfusion, postoperative fever and chronic cough) found to be not associated with increase risk for hernia formation.

\section{Conclusion}

The development of incisional hernia following lower midline cesarean section is not common but higher than previously reported. However, this is still one of the most important causes of morbidity in women in such a relatively youthful age. Number of CSs, wound infection and obesity are the most considerable associated factors. Reduction in fertility can reduce the risk of incisional hernia associated with cesarean delivery, a risk magnified by many successive CSs. Also measures to minimize postoperative wound infection may reduce the incidence.Other comorbidities(DM, heart disease and COPD) were too small to fully evaluate this association, that address the need for future cohort studies with larger sample.

\section{References}

1. Oscar Agüero. Eventraciones poscesárea. Rev Obstet Ginecol Venez v. 65 n.3 Caracas sep. 2005.

2.. Agbakwuru et al. Incisional Hernia in Women: Predisposing Factors and Management Where Mesh is not Readily Available. Libyan Journal of Medicine, Vol 4, No 2 (2009)

3. Johnson JC, Barnes WA. How to choose the right abdominal incision.Ob/Gyn.1993 Contemp, 38 (3) :56-73

4. ADESUNKANMP and B. FALEYIMU. Incidence and aetiological factors of incisional hernia in post-caesarean operations in a Nigerian hospital. Journal of Obstetrics and Gynaecology (May 2003) Vol. 23, No. 3, 258-260

5. Yahchouchy-Chouillard E et al. Incisional hernias. I. Related risk factors. Dig Surg 2003; 20:3-9.

6. Dumont $A$ et al. Cesarean section rate for maternal indication in sub-Saharan Africa: a systematic review. Lancet 2001;358:1328-33

7. Betran AP et al, Rates of cesarean section: analysis of global, regional and national estimates, Paediatr Perinat Epidemiol 2007;21:98-113

8. Smith BL, Martin JA, Ventura SJ, Births and deaths: preliminary data for July 1997-June 1998. Natl Vital Stat Rep 1999;47:1-22.

9. Hamilton BE, Martin JA, Ventura SJ, Births: preliminary data for 2007, National vital statistics reports, Web release, Vol 57. Hyattsville, MD: National Center for Health Statistics; 2009.

10. Millikan KW, Incisional hernia repair, Surg Clin NAm 2003; 83:1223.

11. Makela JT, Kiviniemi H, Laitnew S, Factors influencing wound dehiscence after midline laparotomy, Am J Surg 1995; 170:387-90. 
12. Carlson MA, Ludwig KA, Condon RE, Ventral hernia and other complications of 1000 midline incisions, South Med. J 1995; 88:450-3.

13. Isrealsson LA, Jonsson $T$, Suture length to wound length ratio and healing of midline laparotomy incision, Br. J Surg 1993; 80:1284-6.

14. Rucinski J, Margolis M, Panagopoulos G, Wise L. Closure of abdominal midline fascia: Metaanalysis delineates the optimal technique. Am Surg 2001; 67:412-6.

15. rk AE, Roth JS and Kavic SM. Abdominal wall hernia. Current Problems in Surgery. 2006; 43: 326-375

16. Ibrahim M. Hindawi, Zakarya B. Mer'l. The Jordanian cesarean section rate. Saudi Med J 2004; Vol. 25 (11): 1631-1635

17. Townsend: Sabiston Textbook of Surgery, 18th ed, chapter 44 ventral hernia.

18. Franchi $\mathrm{M}$ et al. Incisional hernia in gynecologic oncology patients: a 10-year study. Obstet Gynecol 2001;97(5 Pt 1): 696-700.
19. Kingsnorth A. The management of incisional hernia. Ann R Coll Surg Engl 2006;88: 252-60.

20. Long $\mathrm{KC}$ et al. Ventral hernia following primary laparotomy for ovarian, fallopian tube, and primary peritoneal cancers. Gynecol Oncol (2010), doi:10.1016/j.ygyno.2010; 09: 015.

21. Ellis H, Gajraj H, George D. Incisional hernias: When do they occur?. Br J Surg 1983;70: $290-1$.

22.. Hesslink $\mathrm{VJ}$ et al . An evaluation of risk factors in incisional hernia recurrence. Surg Gynecol Obstet. 1993 Mar;176(3):228-34.

23. Sorensen et al. Smoking is a risk factor for incisional hernia. ARCh.Surg. 2005 Feb;140(2):119-23.

24. Bellón JM, Durán HJ. Biological factors involved in the genesis of incisional hernia. Cir Esp. 2008 Jan; 83(1):3-7. 